\title{
Simple Nonionic Omnisoluble Tetraphenylporphyrin for Relative Referencing of Singlet Oxygen Quantum Yield
}

Daniel T. Payne ${ }^{1,2}$, Jan Hynek ${ }^{2}$, Jan Labuta² and Jonathan P. Hill ${ }^{2, *}$

${ }^{1}$ International Center for Young Scientists, National Institute for Materials Science, Namiki 1-1, Tsukuba, Ibaraki 305-0044, Japan.

${ }^{2}$ International Center for Materials Nanoarchitectonics, National Institute for Materials Science, Namiki 1-1, Tsukuba, Ibaraki 305-0044, Japan. 


\section{Abstract}

Meso-tetrakis-(3,4,5-tris $\left\{2\right.$-[2-(2-methoxyethoxy)ethoxy]ethoxy\}phenyl)porphyrin $\mathbf{T E G}_{\mathbf{1 2}} \mathbf{P H}_{\mathbf{2}}$ is reported as an 'omnisoluble' TPP reference for singlet oxygen $\left({ }^{1} \mathrm{O}_{2}\right)$ generation quantum yield (Фso) estimation. $\mathrm{TEG}_{12} \mathrm{PH}_{\mathbf{2}}$ is a highly soluble, nonionic compound possessing excellent ${ }^{1} \mathrm{O}_{2}$ QY in a wide variety of common solvents, including water. $\mathbf{T E G}_{12} \mathbf{P H}_{\mathbf{2}}$ was prepared on multigram scale by the 12-way 0-alkylation of tetrakis(3,4,5-trihydroxyphenyl)porphyrin using 2-(2-(2methoxyethoxy)ethoxy)ethyl 4-toluenesulfonate as reaction solvent. The corresponding $\mathrm{Zn}(\mathrm{II})$ complex TEG ${ }_{12}$ PZn was also prepared and studied. Its ${ }^{1} \mathrm{O}_{2} \mathrm{QYs}$ in the different solvents studied were found to be 0.86 (acetone), 0.59 (acetonitrile), 0.66 (chloroform), 0.85 (methanol), 0.45 (toluene) and 0.51 (water). $\mathbf{T E G}_{12} \mathbf{P H}_{2}$ can be considered a reliable and easy to implement omnisoluble reference compound for the estimation of the ${ }^{1} \mathrm{O}_{2}$ generating activities of new materials, especially new porphyrinic compounds.

\section{Graphical Abstract}
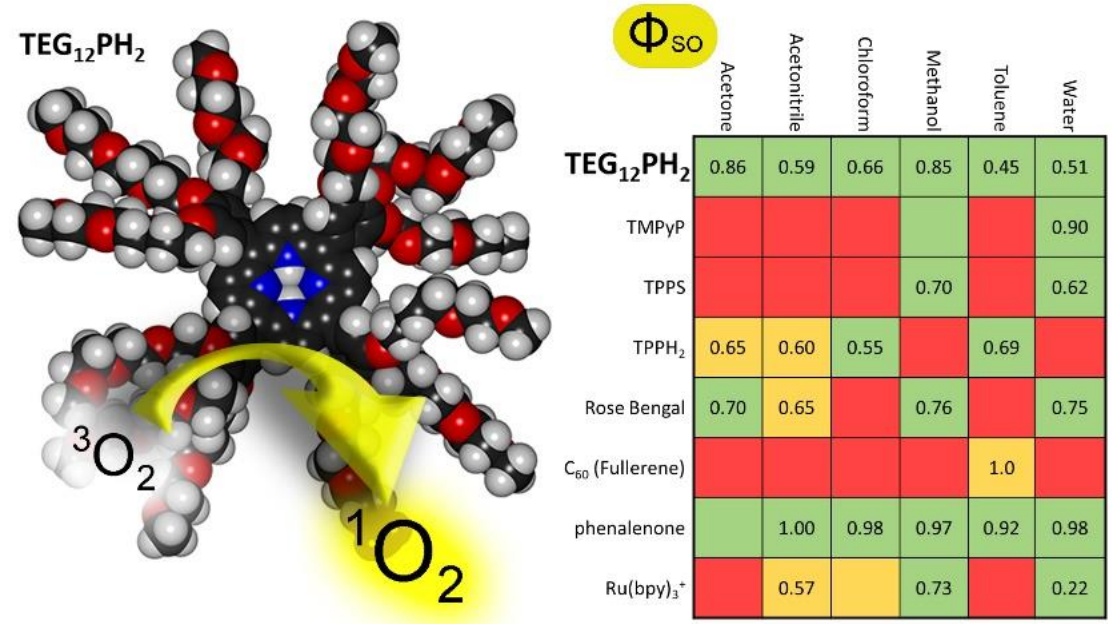


\section{Introduction}

Chromophores possessing electronic structures that allow access to triplet excited states are capable of interacting with molecular oxygen, whose ground state is also a triplet, leading to the generation of singlet oxygen $\left({ }^{1} \mathrm{O}_{2}\right) \cdot{ }^{1,2}{ }^{1} \mathrm{O}_{2}$ is a reactive oxygen species (ROS) often considered deleterious but which is gaining increasing recognition for its positive uses including in organic synthesis, ${ }^{3}$ for elimination of pollutants ${ }^{4}$ (e.g., for water purification ${ }^{5}$ ) and more importantly for photodynamic therapies ${ }^{6}$ involving cancer treatment ${ }^{7}$ or microbial inactivation. ${ }^{8}$ Photodynamic applications rely on the localized destructive properties of ${ }^{1} \mathrm{O}_{2}$ based on its high reactivity with organic materials and moderate lifetime, which allow for instance, selective targeting of tumors. There now exist several promising classes of chromophores (Figure 1) with appropriate properties for implementation of the aforementioned applications with new classes appearing. ${ }^{9}$ ${ }^{1} \mathrm{O}_{2}$-generating properties of these compounds can be screened and assessed by simple comparison with a reference material whose properties under equivalent conditions are known. ${ }^{10}$ Since applications such as PDT are conducted in aqueous media, this requires the availability of water-soluble reference compounds although methods exist for estimating the ${ }^{1} \mathrm{O}_{2}$ quantum yield $\left(\Phi_{\text {so }}\right)$ between different media. ${ }^{11}$ Several useful water-soluble reference materials exist including Rose Bengal (RB; $\Phi_{\text {so }} 0.75$ in water), ${ }^{12}$ tris(2,2'-bipyridine)ruthenium(II) salts $\left(\mathrm{Ru}(\mathrm{Bipy}){ }_{3} \mathrm{Cl}_{2} ; \quad \Phi_{\text {so }} \quad 0.22 \text { in } \quad \text { water }\right)^{13}$ and phenalenone $\left(\mathrm{PN} ; \quad \Phi_{\text {so }} 1.0\right.$ in water). ${ }^{14}$ Tetraphenylporphyrin $\left(\mathrm{TPPH}_{2} ; \Phi_{\text {so }} 0.69 \text { in toluene }\right)^{15}$ has also been used as a convenient reference material in organic solvents being notable for its synthetic flexibility and availability of many transition metal complexes although generally only free base $\left(\mathrm{TPPH}_{2}\right)^{16}$ and zinc(II) complexes (TPPZn $)^{17}$ have been used as ${ }^{1} \mathrm{O}_{2} \Phi_{\text {so }}$ references. Several water-soluble TPP derivatives 
are also available including tetrakis(4-sulfonatophenyl)porphyrin (TPPS) ${ }^{18}$ and tetrakis(methyl-4pyridinium)porphyrin (TMPyP), ${ }^{19}$ which have also been investigated for their PDT properties. ${ }^{20}$ However, the use of these compounds as PDT agents or ${ }^{1} \mathrm{O}_{2} \Phi_{\text {so }}$ references are both compromised by their strong tendencies to aggregate in aqueous media. Aggregation of chromophores is one of the main routes to deactivation of their ${ }^{1} \mathrm{O}_{2}$ generation capabilities representing a significant disadvantage. Furthermore, TPPS and TMPyP are insoluble in non-polar solvents so that cross-media comparisons of relative activity are not convenient and require postprocessing of data. Since $\mathrm{TPPH}_{2}$ derivatives compose a large class of compounds of interest for ${ }^{1} \mathrm{O}_{2}$ generation, it would be useful to establish a cross-medium 'omnisoluble' reference with excitation wavelengths in the visible region to facilitate and standardize the relevant property data and facilitate the estimation of quantum yields of ${ }^{1} \mathrm{O}_{2}$ generation.

In this work, we report such an 'omnisoluble' $\mathrm{TPPH}_{2}$ reference for ${ }^{1} \mathrm{O}_{2}$ QY estimation. Meso-tetrakis-(3,4,5-tris $\left\{2\right.$-[2-(2-methoxyethoxy)ethoxy]ethoxy\}phenyl)porphyrin $\mathbf{T E G}_{12} \mathbf{P H}_{\mathbf{2}}$ is a highly soluble, ${ }^{21}$ nonionic compound possessing excellent ${ }^{1} \mathrm{O}_{2} \mathrm{QY}$ in a variety of common solvents, including water. The properties of the corresponding meso-tetraphenylporphinatozinc(II) compound $\mathrm{TEG}_{12} \mathrm{PZn}$ are also reported and a convenient large scale synthesis of the parent $\mathrm{TEG}_{12} \mathrm{PH}_{2}$ compound is provided. 

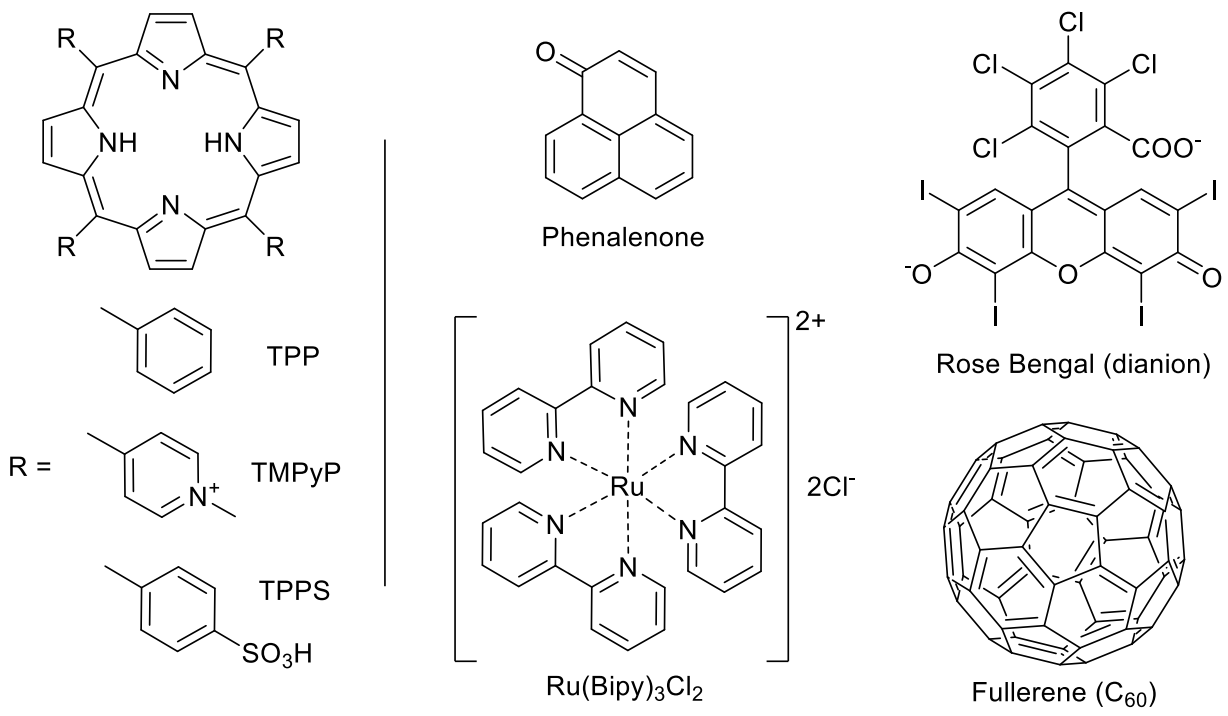

Figure 1. Chromophores commonly used for ${ }^{1} \mathrm{O}_{2}$ photosensitization and as $\Phi_{\text {so }}$ reference compounds. Abbreviations: $\mathrm{TPPH}_{2}$ (5,10,15,20-tetraphenylporphyrin); TMPyP $(5,10,15,20-$ tetrakis(4-methylpyridinium)porphyrin); TPPS (5,10,15,20-tetrakis(4-sulfonatophenyl) porphyrin); $\mathrm{Ru}(\mathrm{Bipy})_{3} \mathrm{Cl}_{2}$ (dichlorotris(2,2'-bipyridyl)ruthenium(II)).

\section{Experimental}

General. Reagents and dehydrated solvents (in septum-sealed bottles) used for syntheses and spectroscopic measurements were obtained from Tokyo Kasei Chemical Co., Wako Chemical Co., Nacalai Tesque Chemical Co. or Aldrich Chemical Co. and were used without further purification. Electronic absorption spectra were measured using JASCO V-570 UV/Vis/NIR spectrophotometer. FTIR spectra were obtained using a Thermo-Nicolet 760X FTIR spectrophotometer equipped with a SMART-iTX ATR accessory. ${ }^{1} \mathrm{H}-\mathrm{NMR}$ spectra and proton decoupled ${ }^{13} \mathrm{C}-\mathrm{NMR}$ spectra were obtained using a JEOL AL400SSS spectrometer operating at 400 $\mathrm{MHz}$ and $101 \mathrm{MHz}$, respectively, with tetramethylsilane as an internal standard. Data were processed using Delta version 5.0.5.1, Always JNM-AL version 6.2 and MestReNova 6.0.2 
programs. ${ }^{1} \mathrm{H}$ NMR chemical shifts $(\delta)$ are reported in ppm relative to $\mathrm{TMS}$ for $\mathrm{CDCl}_{3}(\delta 0.00)$ or the residual solvent peak for other solvents. ${ }^{13} \mathrm{C}$ NMR chemical shifts $(\delta)$ are reported in ppm relative to the solvent reported. Coupling constants $(J)$ are expressed in Hertz $(\mathrm{Hz})$, shift multiplicities are reported as singlet $(s)$, doublet $(d)$, triplet $(t)$, quartet $(q)$, double doublet (dd), multiplet (m) and broad singlet (bs). High resolution electrospray ionization time-of-flight mass spectra (ESI-TOF-MS) were measured using a Thermo Scientific Q-Exactive Plus instrument. Tetrakis(3,4,5-trimethoxyphenyl)porphyrin was prepared according to the method of Adler et $\mathrm{al}^{22}$ (after Albery et $a^{23}$ ) and purified according to Barnett et al. ${ }^{24}$

Tetrakis(3,4,5-trihydroxyphenyl)porphyrin. ${ }^{23}$ Tetrakis(3,4,5-trimethoxyphenyl)porphyrin (2 g, $2.05 \mathrm{mmol}$ ) was dissolved in dichloromethane $(20 \mathrm{~mL})$ and the resulting solution cooled to $0{ }^{\circ} \mathrm{C}$. $\mathrm{BBr}_{3}\left(5 \mathrm{~mL}, 1 \mathrm{M}\right.$ in $\mathrm{CH}_{2} \mathrm{Cl}_{2}$ ) was then added dropwise with stirring followed by stirring at room temperature for $48 \mathrm{~h}$. A second aliquot of $\mathrm{BBr}_{3}\left(5 \mathrm{~mL}, 1 \mathrm{M}\right.$ in $\mathrm{CH}_{2} \mathrm{Cl}_{2}$ ) was added and stirring continued for a further $48 \mathrm{~h}$. Methanol $(20 \mathrm{~mL})$ was carefully added to the reaction mixture and the resulting dark precipitate was filtered and washed with acetone and dichloromethane then dried under reduced pressure yielding the dihydrobromide salt of the title compound which was used in the next step without further purification. Yield $1.45 \mathrm{~g}(73 \%)$.

Meso-tetrakis-(3,4,5-tris\{2-[2-(2-methoxyethoxy)ethoxy]ethoxy\}phenyl)porphyrin, TEG $_{12} \mathbf{P H}_{2}{ }^{25}$ The dihydrobromide salt of tetrakis(3,4,5-trihydroxyphenyl)porphyrin obtained in the previous step $(1.45 \mathrm{~g}, 1.5 \mathrm{mmol})$ was suspended in $\operatorname{TEGTs}^{26}(32 \mathrm{~g}, 0.1 \mathrm{~mol})$ and the resulting mixture was purged with nitrogen gas. Solid anhydrous potassium carbonate (6 g, $43.5 \mathrm{mmol}$ ) was added and the dark colored mixture stirred at $100{ }^{\circ} \mathrm{C}$ for 4 days. The resulting bright redpurple mixture was poured into water followed by extraction with chloroform (100 $\mathrm{mL} \times 2$ ). 
Organic fractions were combined and dried over anhydrous sodium sulfate. Following filtration, the solvents were removed under reduced pressure, and the resulting bright red residue was dissolved in chloroform and chromatographed on silica gel eluting first with chloroform until all TEGTs had been eluted followed by $\mathrm{CHCl}_{3} / 5 \% \mathrm{CH}_{3} \mathrm{OH}$ to elute the porphyrin. Fractions containing the product were combined and solvent removed under reduced pressure. Crude $\mathbf{T E G}_{12} \mathbf{P H}_{\mathbf{2}}$ was further purified by size exclusion chromatography using Biobeads SX-1 eluting with dichloromethane. The latter two chromatography procedures can be repeated until the material is judged to be sufficiently pure by using ${ }^{1} \mathrm{H}-\mathrm{NMR}$ spectroscopy. Overall yield of these procedures is estimated to be $85 \%$. Chemical analyses for $\mathbf{T E G}_{12} \mathbf{P H}_{2}$ are identical with those reported by Lee and Kim. ${ }^{25}$ UV/Vis: $\lambda_{\max }\left(\mathrm{nm} ; \varepsilon / \mathrm{mol}^{-1} \mathrm{dm}^{3} \mathrm{~cm}^{-1}\right):\left(\mathrm{CH}_{3}\right)_{2} \mathrm{C}=0: 422\left(2.67 \times 10^{5}\right), 515(12,300), 551$ (5,700), 592 (3,700), 648 (2,900); $\mathrm{CH}_{3} \mathrm{CN}: 421$ (2.86 × 105 , 515 (12,600), 551 (5,200), $590(3,600)$, 647 (2,700); $\mathrm{CHCl}_{3}: 425\left(2.98 \times 10^{5}\right), 518(12,900), 555(5,800), 592(4,200), 648(3,000) ; \mathrm{CH}_{3} \mathrm{OH}:$ $420\left(2.89 \times 10^{5}\right), 516(13,000), 551(5,800), 590(3,900), 648(2,800) ; \mathrm{C}_{6} \mathrm{H}_{5} \mathrm{CH}_{3} 426\left(2.85 \times 10^{5}\right)$, 518 (11,700), 554 (5,600), 593 (3,700), $651(3,000) ; \mathrm{H}_{2} \mathrm{O} 409\left(1.39 \times 10^{5}\right), 420\left(1.39 \times 10^{5}\right), 519$ (9,000), 556 (4,300), 589 (3,100), 648 (2,100). ${ }^{1} \mathrm{H} \mathrm{NMR}\left(\mathrm{CDCl}_{3}, 400 \mathrm{MHz}, 298 \mathrm{~K}\right): \delta=8.89$ (s, 8H), $7.47(\mathrm{~s}, 8 \mathrm{H}), 4.52(\mathrm{t}, J=5.2 \mathrm{~Hz}, 8 \mathrm{H}), 4.31(\mathrm{t}, J=4.6 \mathrm{~Hz}, 16 \mathrm{H}), 4.04(\mathrm{t}, J=5.0 \mathrm{~Hz}, 8 \mathrm{H}), 3.91(\mathrm{~m}, 24 \mathrm{H})$, $3.75(\mathrm{~m}, 32 \mathrm{H}), 3.63(\mathrm{~m}, 24 \mathrm{H}), 3.53(\mathrm{~m}, 16 \mathrm{H}), 3.41(\mathrm{~s}, 3 \mathrm{H}), 3.38(\mathrm{~m}, 24 \mathrm{H}), 3.23(\mathrm{~s}, 24 \mathrm{H}),-2.83(\mathrm{~s}, 2 \mathrm{H})$ ppm. ${ }^{13} \mathrm{CNMR}\left(\mathrm{CDCl}_{3}, 100 \mathrm{MHz}, 298 \mathrm{~K}\right): \delta=150.87,138.24,137.44,119.89,115.11,72.59,71.97$, 71.87, 70.92, 70.76, 70.73, 70.69, 70.65, 70.54, 70.38, 69.91, 61.80, 59.15, 59.11, 58.98 ppm. FTIR (ATR): $v=3320.3$ (w, N-H(str.)), 2871.9 (s, C-H(str.)), 1641.5 (w, C=C(str.)), 1577.4 (m, C=C(str.)), 1559.3 (w), 1540.4 (w), 1497.2 (m), 1471.1 (m, C-H(def.)), 1452.9 (m, C-H(def.)), 1418.5 (m, CH(def.)), 1349.5 (m, C-H(def.)), 1330.7 (w), 1297.5 (w), 1238.7 (m), 1199.4 (w), 1094.9 (vs, C- 
O(str.)), 1027.7 (m, C-O(str.)), $978.9(w), 929.9(m), 886.5(w), 849.1(m), 805.1(m), 761.7(w)$, $738.5(\mathrm{~m}), 664.0$ (w) cm ${ }^{-1}$. HR-MS (ESI-TOF; methanol): $\mathrm{m} / \mathrm{z}$ calc'd for $\left[\mathrm{C}_{128} \mathrm{H}_{197} \mathrm{O}_{48} \mathrm{~N}_{4}{ }^{+}\right]: 2558.3092$ amu, found: 2558.2944 amu.

Meso-tetrakis-(3,4,5-tris\{2-[2-(2-methoxyethoxy)ethoxy]ethoxy\}phenyl)porphyrinatozinc(II), TEG 12 PZn. TEG $12 P_{2} H_{2}$ was treated with zinc(II) acetate in chloroform/methanol according to a literature method. ${ }^{27}$ The crude product was purified using column chromatography ( $\mathrm{SiO}_{2} / \mathrm{CHCl}_{3}: \mathrm{CH}_{3} \mathrm{OH}$ 19:1) and size exclusion chromatography (BioBeads $\mathrm{SX}-1 / \mathrm{CH}_{2} \mathrm{Cl}_{2}$ ). UV/Vis: $\lambda_{\max }$ $\left(\mathrm{nm} ; \varepsilon / \mathrm{mol}^{-1} \mathrm{dm}^{3} \mathrm{~cm}^{-1}\right):\left(\mathrm{CH}_{3}\right)_{2} \mathrm{C}=\mathrm{O}: 427\left(3.89 \times 10^{5}\right), 557(14,400), 597(5,400) ; \mathrm{CH}_{3} \mathrm{CN}: 427(4.01$ $\left.\times 10^{5}\right), 557(14,900), 597(5,500) ; \mathrm{CHCl}_{3}: 427\left(4.11 \times 10^{5}\right), 556(15,900), 596(4,800) ; \mathrm{CH}_{3} \mathrm{OH}: 426$ $\left(5.00 \times 10^{5}\right), 558(17,800), 598(6,700) ; \mathrm{C}_{6} \mathrm{H}_{5} \mathrm{CH}_{3} 429\left(3.64 \times 10^{5}\right), 556(14,300), 597(5,000) ; \mathrm{H}_{2} \mathrm{O}$ $427\left(2.56 \times 10^{5}\right), 560(14,000), 600(6,100) .{ }^{1} \mathrm{H} \mathrm{NMR}\left(\mathrm{CDCl}_{3}, 400 \mathrm{MHz}, 298 \mathrm{~K}\right): \delta=8.94(\mathrm{~s}, 8 \mathrm{H}), 7.49$ (s, 8H), $4.52(\mathrm{t}, J=4.9 \mathrm{~Hz}, 8 \mathrm{H}), 4.31(\mathrm{t}, J=4.4 \mathrm{~Hz}, 16 \mathrm{H}), 4.04(\mathrm{t}, J=5.0 \mathrm{~Hz}, 8 \mathrm{H}), 3.91(\mathrm{~m}, 24 \mathrm{H}), 3.75$ $(\mathrm{m}, 32 \mathrm{H}), 3.63(\mathrm{~m}, 24 \mathrm{H}), 3.53(\mathrm{~m}, 16 \mathrm{H}), 3.41(\mathrm{~s}, 3 \mathrm{H}), 3.38(\mathrm{~m}, 24 \mathrm{H}), 3.23(\mathrm{~s}, 24 \mathrm{H}) \mathrm{ppm} .{ }^{13} \mathrm{C} \mathrm{NMR}$ $\left(\mathrm{CDCl}_{3}, 100 \mathrm{MHz}, 298 \mathrm{~K}\right): \delta=150.65,150.05,138.46,138.01,131.89,120.64,115.38,71.95,71.42$, $70.92,70.88,70.76,70.69,70.66,70.64,70.53,70.19,61.78,59.16,59.10,58.64$ ppm. FTIR (ATR): $v=2871.7$ (s, C-H(str.)), 1641.2 (w, C=C(str.)), 1576.9 (m, C=C(str.)), 1560.4 (w), 1540.2 (w), 1521.5 (w), 1486.5 (m, C-H(def.)), 1452.8 (m, C-H(def.)), 1417.5 (m, C-H(def.)), 1344.8 (m, C-H(def.)), $1316.3(w), 1291.2(w), 1239.5(m), 1202.3(w), 1094.5$ (vs, C-O(str.)), 1027.8 (m, C-O(str.)), 1000.3 (w), $950.8(\mathrm{~m}), 849.3(\mathrm{~m}), 797.7(\mathrm{~m}), 762.6(\mathrm{w}), 723.4(\mathrm{~m}), 663.0(\mathrm{w}), 645.6(\mathrm{w}) \mathrm{cm}^{-1}$. HR-MS (ESITOF; methanol): $\mathrm{m} / \mathrm{z}$ calc'd for $\left[\mathrm{C}_{128} \mathrm{H}_{196} \mathrm{O}_{48} \mathrm{~N}_{4} \mathrm{ZnNa}^{+}\right]: 2644.2203 \mathrm{amu}$, found: $2644.2300 \mathrm{amu}$.

${ }^{1} \mathrm{O}_{2}$ Quantum Yield Measurements. ${ }^{1} \mathrm{O}_{2}$ photoluminescence spectra were measured using a Horiba Jobin Yvon Fluorolog NIR spectrofluorimeter equipped with an $\mathrm{N}_{2}$-cooled InGaAs NIR 
detector. A right-angle detection method and quartz curvettes with 4 polished faces were used for emission measurements. Solutions of $\mathbf{T E G}_{12} \mathbf{P H}_{\mathbf{2}}$ and $\mathbf{T E G}_{12} \mathbf{P Z n}$ were absorbance normalized (ca. $0.15-0.3$ a.u.) with the reference compound at the relevant excitation wavelength in the different solvents. Singlet oxygen quantum yields $\left(\Phi_{\mathrm{so}}\right)$ were determined by comparison of the ${ }^{1} \mathrm{O}_{2}$ photoluminescence maxima values of the reference $\left(\mathrm{I}_{\text {ref }}\right)$ and compound being studied $\left(\mathrm{I}_{\text {sample }}\right)$ at approximately $1270 \mathrm{~nm}$ using the formula:

$$
\Phi_{S O}=\frac{I_{\text {sample }}}{I_{\text {ref }}} \times \Phi_{\text {so }}^{\text {ref }}
$$

\section{Results and Discussion}
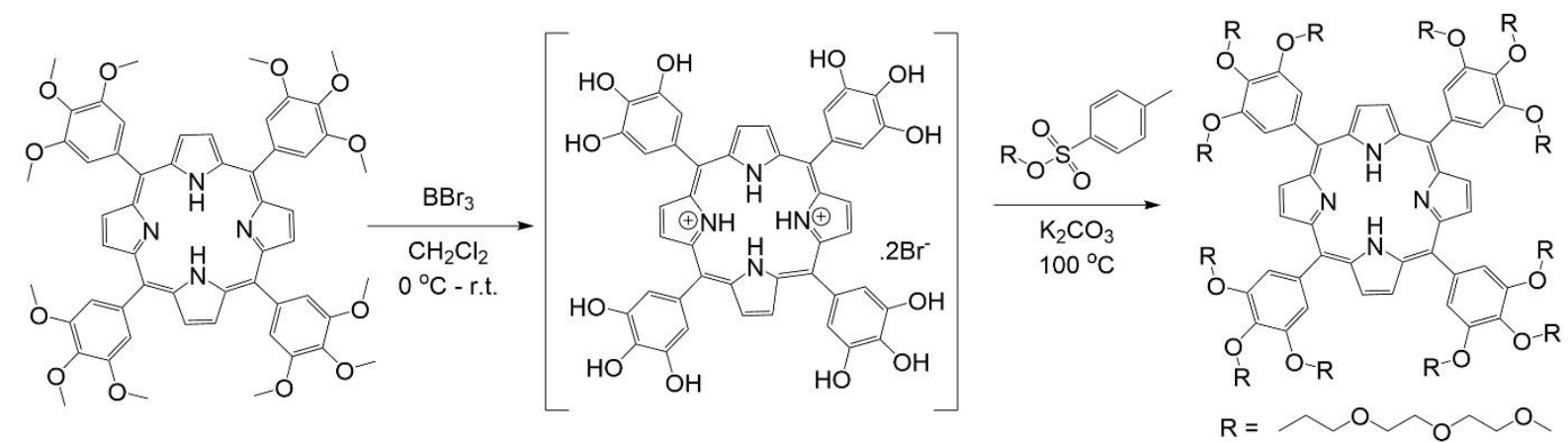

Scheme 1. Preparation of $\mathbf{T E G}_{12} \mathbf{P H}_{2}$ from tetrakis(3,4,5-trimethoxyphenyl)porphyrin. Tetrakis(3,4,5-trihydroxyphenyl)porphyrin dihydrobromide was isolated by filtration and used without further purification. Triethylene glycol monomethyl ether tosylate was used as reaction solvent in the O-alkylation step.

\section{Synthesis}

As shown in Scheme 1, $\mathbf{T E G}_{12} \mathbf{P H}_{2}$ was prepared in two steps from tetrakis $(3,4,5$ trimethoxyphenyl)porphyrin. Tetrakis(3,4,5-trimethoxyphenyl)porphyrin was prepared according to the method of Adler et $a l^{22}$ (after Albery et $a l^{23}$ ) and purified according to Barnett et al. ${ }^{24}$ The purified porphyrin was treated with $\left.\mathrm{BBr}_{3}{ }^{23}\right)$ to give tetrakis $(3,4,5-$ 
trihydroxyphenyl)porphyrin, which was subsequently reacted with 2-(2-(2methoxyethoxy)ethoxy)ethyl 4-toluenesulfonate (TEGTs) in the presence of potassium carbonate. The O-alkylation of tetrakis(3,4,5-trihydroxyphenyl)porphyrin is significantly more effective for the preparation of $\mathbf{T E G}_{12} \mathbf{P H}_{\mathbf{2}}$ than preparing the corresponding benzaldehyde followed by acid catalyzed condensation with pyrrole due to the low yields generally obtained for the triple O-alkylation of 3,4,5-trihydroxybenzaldehyde using tosylates. ${ }^{28}$ Using our procedure, it is possible to prepare large multigram batches of $\mathbf{T E G}_{12} \mathbf{P H}_{2}$. It was found convenient to use TEGTs also as solvent in the O-alkylation procedure with excess of that reagent being recycled following completion of the reaction. $\mathbf{T E G}_{12} \mathbf{P H}_{2}$ was isolated by flash column chromatography $\left(\mathrm{SiO}_{2}\right.$; gradient elution $\mathrm{CHCl}_{3}-\mathrm{CHCl}_{3} / 5 \%$ methanol). The resulting red oil was then purified by size exclusion chromatography (Biobeads $\mathrm{SX}-1, \mathrm{CH}_{2} \mathrm{Cl}_{2}$ ). For convenience, these purification procedures were performed on $1 \mathrm{~g}$ batches of the crude product obtained by flash chromatography. $\mathrm{TEG}_{12} \mathrm{PH}_{2}$ prepared by this method is identical with that prepared previously by Lee and Kim. ${ }^{25}$ TEG $_{12}$ PZn was also prepared during this study.

The chemical structure of $\mathrm{TEG}_{12} \mathrm{PH}_{2}$ and a 3-dimensional structure obtained using $\mathrm{MM} 2$ energy minimization are shown in Figure 2. $\mathbf{T E G}_{12} \mathbf{P H}_{\mathbf{2}}$ has a relatively large molecular weight with a diameter around $3.5 \mathrm{~nm}$ for conformations involving extended substituents. In non-polar solvents this is expected to be considerably lower based on intramolecular $\mathrm{H}$-bonding interactions and non-extended conformations of the chains caused by O-atom substitution. 

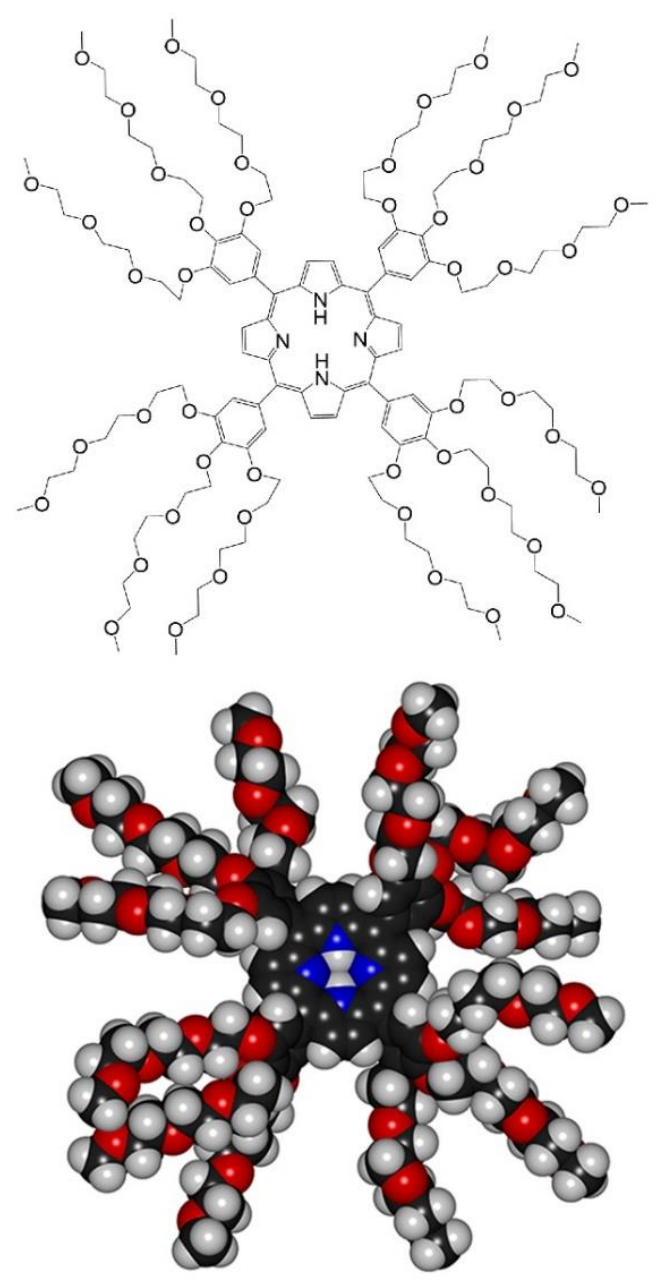

Figure 2. Molecular structure of $\mathbf{T E G}_{12} \mathbf{P H}_{2}$. Upper: chemical structure showing the porphyrin macrocycle with highly substituted meso-phenyl substituents. Lower: space-filling model of an energy minimized ( $\mathrm{MM} 2$ in Chemdraw 3D) structure of $\mathbf{T E G}_{12} \mathbf{P H}_{2}$. Non-all-trans conformations of the substituents are also favored in highly oxa-substituted O-alkyl chains.

\section{Singlet Oxygen Generation}

Studies of ${ }^{1} \mathrm{O}_{2}$ photosensitization using organic chromophores are usually conducted in the solution state with estimations of $\Phi_{\text {so }}$ based on comparison with a known reference standard material such as $\mathrm{RB},{ }^{12,29} \mathrm{PN}$ derivatives ${ }^{14,30}$ or tetraphenylporphyrin derivatives. ${ }^{15-19,31}$ Selection of a material as reference is dictated by the solubility of the prospective reference in the required solvent(s) and its absorption spectrum in those solvents (it should have a significant absorbance 
at the required excitation wavelength for normalization). $\mathbf{T E G}_{12} \mathbf{P H}_{\mathbf{2}}$ is a tetraphenylporphyrin $\left(\mathrm{TPPH}_{2}\right)$ derivative exhibiting sufficient solubility/miscibility (it is a liquid at r.t.p.) in many solvents including polar and non-polar solvents commonly used for $\Phi_{\text {so }}$ studies. For this reason, we have studied the $\Phi_{\text {so }}$ of TEG $_{12} \mathbf{P H}_{2}$ using phosphorescence spectroscopy in different solvents. Relevant electronic absorption and singlet oxygen phosphorescence spectral data is shown in Figure 3 for acetone, acetonitrile, chloroform, methanol, toluene and water. Also, shown in each panel of Figure 3 are the normalized electronic absorption spectra of the reference compound used for the estimation of $\Phi_{\text {so }}$ according to the relative intensities of the corresponding ${ }^{1} \mathrm{O}_{2}$ phosphorescence spectra in the NIR region $(1270 \mathrm{~nm})$, which are shown in the insets of each figure. The values of $\Phi_{\text {so }}$ of $\mathbf{T E G}_{12} \mathbf{P H}_{\mathbf{2}}$ obtained from the data shown in Figure 3 are summarized in Table 1. TEG $\mathbf{1}_{\mathbf{2}} \mathbf{P H}_{\mathbf{2}}$ is highly miscible with acetone, acetonitrile, chloroform, methanol, toluene and water at all proportions studied with only a minor solvatochromatic shift observed in the absorption maxima of the Soret band. Extinction coefficients (Table 1) are consistent with those reported for other tetraphenylporphyrin derivatives, except for $\mathbf{T E G}_{12} \mathbf{P H}_{\mathbf{2}}$ in water, which shows a lower than expected value probably due to aggregation as indicated by the enhanced absorption shoulder on the short wavelength side of its Soret band and its lower extinction coefficient. ${ }^{32} \Phi_{\text {so }}$ values between 0.45 and 0.86 obtained for TEG $_{12}$ PH $_{2}$ were determined relative to known literature references (either $\mathrm{TPPH}_{2}$ or $\mathrm{Ru}(\mathrm{Bipy})_{3} \mathrm{Cl}_{2}$ ) each in the same solvent to eliminate errors introduced by the use of solvent correction factors. 

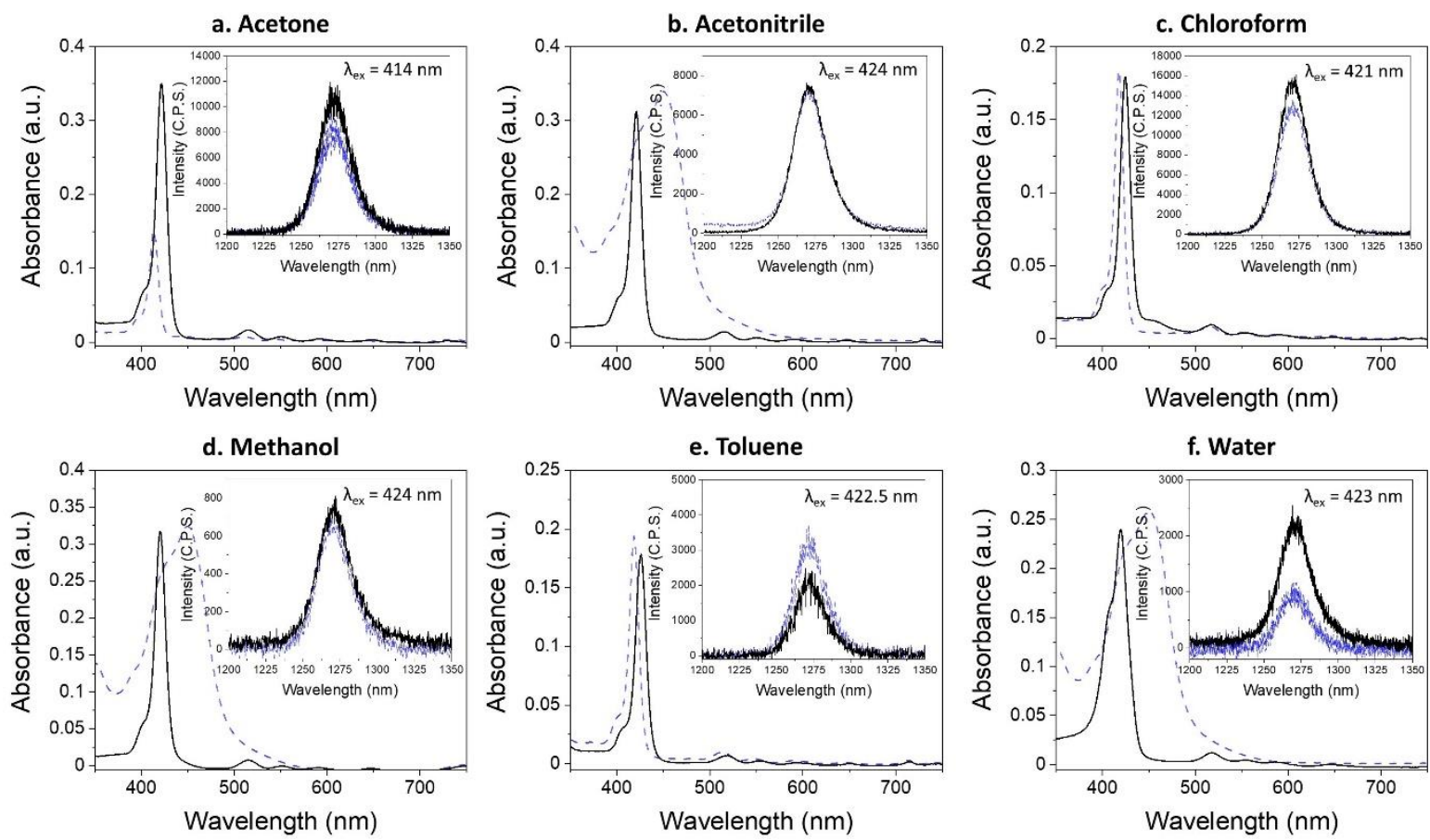

Figure 3. UV-Vis absorption and ${ }^{1} \mathrm{O}_{2}$ phosphorescence (inset) spectra of $\mathbf{T E G}_{12} \mathbf{P H}_{\mathbf{2}}$ (black solid lines) and references (blue dashed line) in various solvents. (a) Acetone, normalized to TPP at 414 $\mathrm{nm}$. (b) Acetonitrile, normalized to $\mathrm{Ru}$ (bipy) ${ }_{3} \mathrm{Cl}_{2}$ at $424 \mathrm{~nm}$. (c) Chloroform, normalized to TPP at $421 \mathrm{~nm}$. (d) Methanol, normalized to $\mathrm{Ru}$ (bipy) ${ }_{3} \mathrm{Cl}_{2}$ at $424 \mathrm{~nm}$. (e) Toluene, normalized to TPP at $422.5 \mathrm{~nm}$. (f) $\mathrm{D}_{2} \mathrm{O}$, normalized to $\mathrm{Ru}$ (bipy) ${ }_{3} \mathrm{Cl}_{2}$ at $423 \mathrm{~nm}$.

Table 1. Photophysical properties of $\mathrm{TEG}_{12} \mathrm{PH}_{2}$ in different solvents

\begin{tabular}{|c|c|c|c|c|}
\hline Solvent & $\boldsymbol{\lambda}_{\max }(\mathbf{n m})$ & $\boldsymbol{\varepsilon}\left(\mathbf{M}^{\mathbf{- 1}} \mathbf{~ c m}^{-\mathbf{1}}\right)$ & Intensity (C.P.S.) & $\boldsymbol{\Phi}_{\text {so }}$ \\
\hline Acetone & 422 & $266,700 \pm 7200$ & 10423 & $0.86^{\mathrm{a}}$ \\
\hline Acetonitrile & 421 & $285,500 \pm 900$ & 7268 & $0.59^{\mathrm{b}}$ \\
\hline Chloroform & 425 & $298,200 \pm 2200$ & 15036 & $0.66^{\mathrm{c}}$ \\
\hline Methanol & 421 & $288,700 \pm 800$ & 747 & $0.85^{\mathrm{d}}$ \\
\hline Toluene & 426 & $284,500 \pm 5200$ & 2052 & $0.45^{\mathrm{e}}$ \\
\hline Water & 420 & $138,700 \pm 1600$ & 2161 & $0.51^{\mathrm{f}}$ \\
\hline
\end{tabular}

a Compared to $\mathrm{TPPH}_{2}$ (intensity $\left.-7861, \Phi_{\mathrm{so}}-0.65\right)$; Ref. 33.

b Compared to Ru(Bipy) $3^{2+}$ (intensity - 6963, $\Phi_{\text {so }}-0.57$ ); Ref. 34.

c Compared to $\mathrm{TPPH}_{2}$ (intensity - 12567, $\Phi_{\mathrm{so}}-0.55$ ); Ref. 35.

${ }^{d}$ Compared to Ru(Bipy) ${ }_{3}{ }^{2+}$ (intensity $-644, \Phi_{\text {so }}-0.73$ ); Ref. 34.

e Compared to $\mathrm{TPPH}_{2}$ (intensity - 3080, $\Phi_{\mathrm{So}}-0.68$ ); Ref. 15.

${ }^{f}$ Measurements carried out in $\mathrm{D}_{2} \mathrm{O}$. Compared to Ru(Bipy) ${ }_{3}{ }^{2+}$ (intensity $-930, \Phi_{\text {so }}-0.22$ ); Ref. 13 
TEG ${ }_{12} \mathrm{PH}_{2}$ exhibits excellent $\Phi_{\text {so }}$ in each of the solvents studied. For ease of comparison with the other commonly used $\Phi_{\text {so }}$ reference materials Figure 4 shows values for $\Phi_{\text {so }}$ in different solvents (where available). Notably, phenalenone is the only other compound exhibiting sufficient solubility in a range of solvents. The appropriate functionalization of any of the dyes might establish solubility in a selected solvent (see Ref. 30 for other phenalenone derivatives). However, $\mathbf{T E G}_{12} \mathrm{PH}_{2}$ is a single compound with excellent solubility/miscibility in most solvents (even beyond those studied here) facilitating cross-solvent comparisons without requiring additional synthetic modifications of the chromophore. Obviously, any cross-solvent comparisons must also take into consideration different properties of the reference molecule in the individual solvents although the use of a single compound avoids the necessity of strident variations in chemical structure which might be required to establish solubility of any particular chromophore in any particular solvent (e.g., introduction of methyl-4-pyridinium groups to solubilize $\mathrm{TPPH}_{2}$ in water). In fact, $\mathrm{TEG}_{12} \mathrm{PH}_{\mathbf{2}}$ combines the solubility characteristics of TMPyP, TPPS and $\mathrm{TPPH}_{2}$, still achieving similar $\Phi_{\text {so }}$ values, but obviating the requirement for multiple reference compounds. From Figure 4, it can be appreciated that PN also possesses substantial cross-solvent solubility although the usefulness of this compound is not available for excitation above $420 \mathrm{~nm}$. However, $\mathbf{T E G}_{12} \mathbf{P H}_{\mathbf{2}}$ has additional absorbance maxima in the visible region (socalled Q-bands), which can also be excited for singlet oxygen generation. Several of the currently used reference compounds (e.g., TMPyP, TPPS, Rose Bengal and $\mathrm{Ru}(\mathrm{bpy})_{3} \mathrm{Cl}_{2}$ ) are charged in solution and can perturb the solution $\mathrm{pH}$ in protic media while $\mathbf{T E G}_{12} \mathbf{P H}_{\mathbf{2}}$ is inactive in this respect due to its neutral hydrophilic structure. 


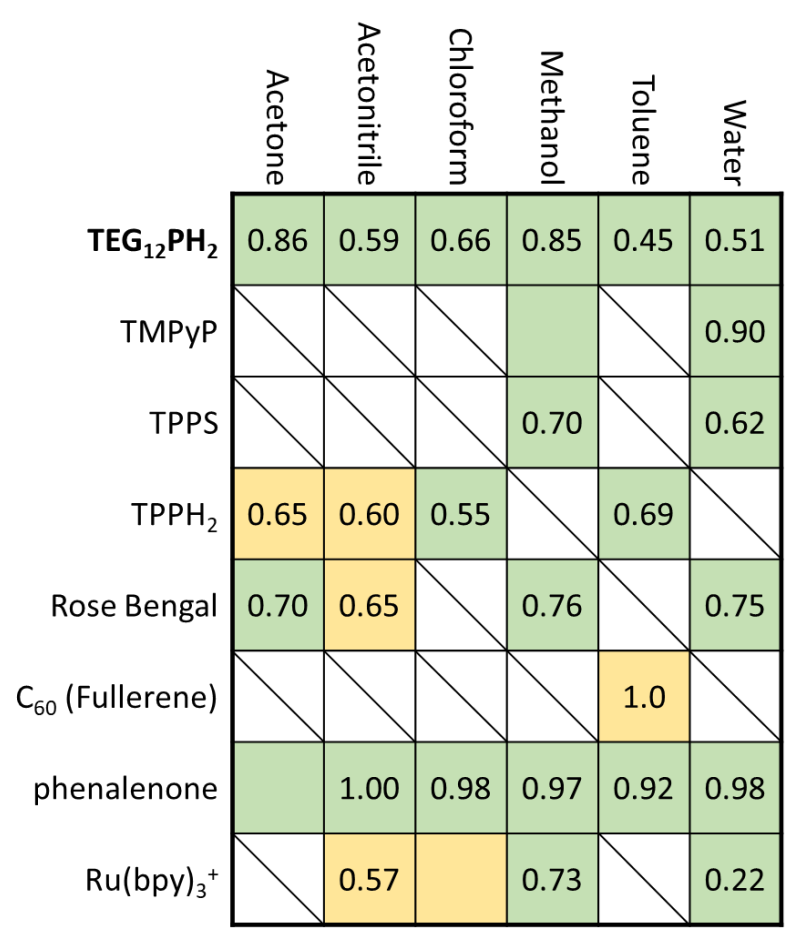

Figure 4. Comparison of solubility and $\Phi_{\text {so }}$ of $\mathrm{TEG}_{12} \mathrm{PH}_{2}$ compared to common literature reported references. Solubility level is represented by the colour of shading. Green: highly soluble (>10 mg $\mathrm{mL}^{-1}$ ), orange: poorly soluble, white: insoluble. TMPyP: ref. 19; TPPS: ref. 18; $\mathrm{TPPH}_{2}$ : refs. 15, 33, 35; Rose Bengal (RB): ref. 12, 36; $C_{60}$ : ref. 35; phenalenone (PN): ref. 14; Ru(bpy) ${ }^{2+}$ : refs. 13, 34.

Stability of $\mathbf{T E G}_{12} \mathbf{P H}_{\mathbf{2}}$ compared to the commonly used reference compounds was assessed by continuous irradiation of normalized solutions of the compounds (Figure 5a) at the absorption maxima whilst monitoring the SO emission signal intensity at $1270 \mathrm{~nm}$ (Figure 5b). The commonly used reference material TPPS and $\mathbf{T E G}_{12} \mathbf{P H}_{\mathbf{2}}$ are somewhat susceptible to loss of activity (losing 20 - 30\% activity within 20 min; see Figure 5b) but are sufficiently stable on the timescale of these measurements to be used to estimate $\Phi_{\text {so. Notably, TMPyP appears of }}$ excellent stability under the same conditions exhibiting no loss of activity over the same time period of irradiation, albeit with a lower phosphorescence intensity. We note here that TEG $_{12} \mathbf{P Z n}$ is not suitable for use in the context of this work despite TPPZn being a very commonly applied 
compound for this purpose. During measurements to assess $\Phi_{\text {so }}$ of $T_{E G_{12}} P Z n$, it was found that irradiation of its solutions led to the rapid (within $120 \mathrm{~s}$ ) and irreversible loss of their singlet oxygen generating capacity as shown in Figure 5 . These observations suggest that aggregative processes of the porphyrins might play a role in loss of activity in water since both TPPS and $\mathrm{TEG}_{12} \mathrm{PZn}$ undergo aggregation in solution - for the former through J-aggregation ${ }^{37}$ and for the latter through coordinative interactions ${ }^{38}$ involving ethylene glycol substituents and $\mathrm{Zn}(\mathrm{II})$ coordinated at the porphyrin moiety. The profound loss of activity in $\mathrm{TEG}_{12} \mathbf{P Z n}$ suggests decomposition or photobleaching (details of these matter will be reported elsewhere).

a.

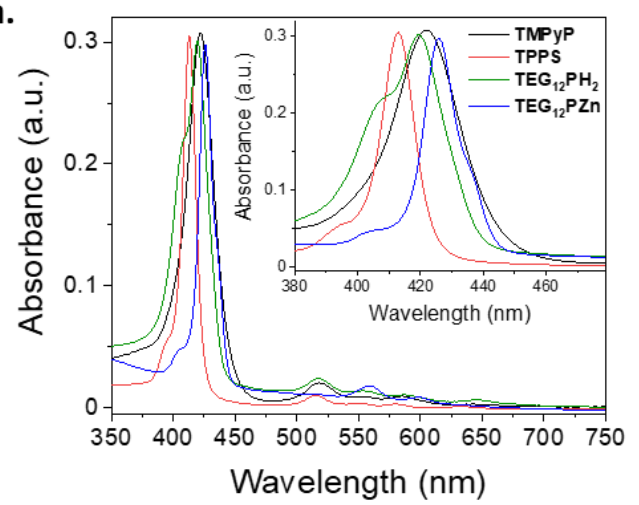

b.

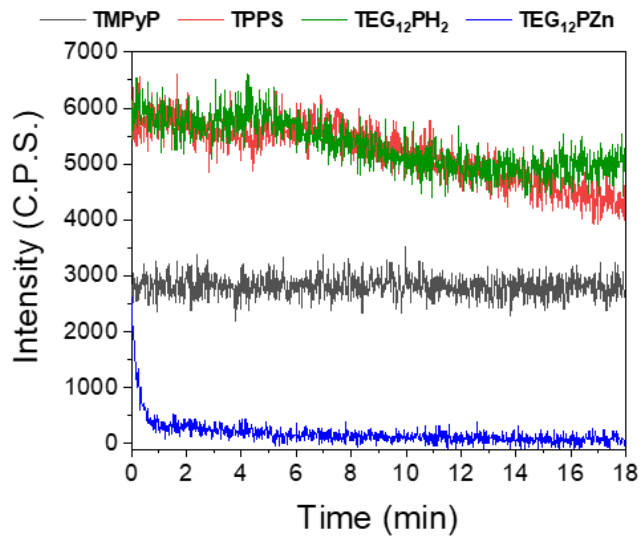

Figure 5. Photostability studies of $\mathrm{TEG}_{12} \mathbf{P H}_{2}$ and $\mathrm{TEG}_{12} \mathbf{P Z n}$ in $\mathrm{D}_{2} \mathrm{O}$. (a) UV-Vis absorption spectra of $\mathrm{TEG}_{12} \mathrm{PH}_{2}$ (Green), TEG ${ }_{12} \mathrm{PZn}$ (Blue), TMPyP (Black) and TPPS (Red) in $\mathrm{D}_{2} \mathrm{O}$ with the Soret band absorption normalized to ca. 0.3 a.u. (b) ${ }^{1} \mathrm{O}_{2}$ phosphorescence kinetics measurements of 
TEG $_{12}$ PH $_{2}$ (Green), TEG 12 PZn (Blue), TMPyP (Black) and TPPS (Red) in $\mathrm{D}_{2} \mathrm{O}$ irradiated at 419, 426, 421 and $413 \mathrm{~nm}$, respectively, with monitoring of the intensity of the phosphorescence signal at $1270 \mathrm{~nm}$.

\section{Conclusion}

In summary, we propose the meso-tetraphenylporphyrin derivative $\mathbf{T E G}_{12} \mathbf{P H}_{\mathbf{2}}$ as a convenient reference material for the estimation of quantum yields of singlet oxygen photosensitization involving solution state organic chromophores in different polar and non-polar solvents including water. Our recent work on ${ }^{1} \mathrm{O}_{2}$ generation involving different types of materials ${ }^{39,40}$ has revealed the importance of having available a reliable and easy to implement reference compound for the estimation of the activities of new materials. $\mathbf{T E G}_{12} \mathbf{P H}_{2}$ can be considered such a compound although we note that the TEG ${ }_{12} \mathbf{P Z n}$ derivative is not suitable for this purpose due its instability under irradiation.

\section{References}

1. A. Kashyap, E. Ramasamy, V. Ramalingam, M. Pattabiraman, Supramolecular control of singlet oxygen generation. Molecules 2021, 26, 2673.

2. X. Li, S. Kolemen, J. Yoon, E. U. Akkaya, Activatable photosensitizers: agents for selective photodynamic therapy. Adv. Funct. Mater. 2007, 27, 1604053.

3. A. A. Ghogare, A. Greer, Using singlet oxygen to synthesize natural products and drugs. Chem. Rev., 2016, 116, 9994-10034. 
4. I. Pibiri, S. Buscemi, A. P. Picciolello, A. Pace, Photochemically produced singlet oxygen: applications and perspectives. ChemPhotoChem 2018, 2, 535-547.

5. D. Garcia-Fresnadillo, Singlet oxygen photosensitizing materials for point-of-use water disinfection with solar reactors. ChemPhotoChem, 2018, 2, 512-534.

6. L. Benov, Photodynamic therapy: current status and future directions. Med. Princ. Pract. 2015, 24 (Suppl 1), 14-28.

7. G. Gunaydin, E. M. Gedik, S. Ayan, Photodynamic therapy - current limitations and novel approaches. Front. Chem. (Lausanne, Switz.) 2021, 9, 691697.

8. C. Vera, F. Tulli, C. D. Borsarelli, Photosensitization with supramolecular arrays for enhanced antimicrobial photodynamic tretaments. Front. Bioeng. Biotechnol. 2021, Ahead of print. DOI: 10.3389/fbioe. 2021.655370

9. J. Hynek, M. K. Chahal, D. T. Payne, J. Labuta, J. P. Hill, Porous Framework Materials for Singlet Oxygen Generation. Coord. Chem. Rev. 2020, 425, 213541.

10. S. Nonell, C. Flors, In Singlet Oxygen Applications in Biosciences and Nanosciences; S. Nonell, C. Flors Ed.; The Royal Society of Chemistry: Cambridge (UK), 2016; Vol. 2, chapter 25, p 9-26.

11. O. Shimizu, J. Watanabe, K. Imakubo, S. Naito, Determination of Phosphorescence Quantum Yield of Singlet Oxygen $\mathrm{O}_{2}\left({ }^{1} \Delta_{g}\right)$ Photosensitized by Phenalenone in Air-Saturated Carbon Tetrachloride. J. Phys. Soc. Jpn. 1998, 67, 3664-3667.

12. P. Murasecco-Suardi, E. Gassmann, A. M. Braun, E. Oliveros, Determination of the quantum yield of intersystem crossing of Rose Bengal. Helv. Chim. Acta 1987, 70, 1760-1773. 
13. D. Garcia-Fresnadillo, V. Georgiadou, G. Orellana, A. M. Braun, E. Oliveros, Singlet oxygen $\left({ }^{1} D_{g}\right)$ production by ruthenium(II) complexes containing polyazaheterocyclic ligands in methanol and water. Helv. Chim. Acta 1996, 79, 1222-1238.

14. R. Schmidt, C. Tanielian, R. Dunsbach, C. Wolff, Phenalenone, a universal reference compound for the determination of quantum yields of singlet oxygen $\mathrm{O}_{2}\left({ }^{1} \mathrm{D}_{\mathrm{g}}\right)$ sensitization. J. Photochem. Photobiol. A: Chem. 1994, 79, 11-17.

15. K.-K. Wang, K.-H. Choi, H.-W. Shin, B.-J. Kim, J.-E. Im, S.-L. Oh, N.-S. Park, M. Jung, J.-B. Oh, M.J. Lee, H.-K. Kim, Y.-R. Kim, Photophysics of a new photosensitizer with high quantum yield of singlet oxygen generation and its application to stereo-selective synthesis of (+)deoxoartemisinin. Chem. Phys. Lett. 2009, 482, 81-86.

16. P. Rothemund, A new porphyrin synthesis. The synthesis of porphin. J. Am. Chem. Soc. 1936, $58,625-627$.

17. W. R. Scheidt, M. E. Kastner, K. Hatano, Stereochemistry of the toluene solvate of a,b,c,dtetraphenylporphinatozinc(II). Inorg. Chem. 1978, 17, 706-710.

18. J. Mosinger, Z. Mička, Quantum yields of singlet oxygen of metal complexes of mesotetrakis(sulphonatophenyl)porphine. J. Photochem. Photobiol. A: Chem. 1997, 107, 77-82.

19. N. N. Kruk, B. M. Dzhagarov, V. A. Galievsky, V. S. Chirvony, P.-Y. Turpin. Photophysics of the cationic 5,10,15,20-tetrakis(4-N-methylpyridyl)porphyrin bound to DNA, [pol(dA-dT) $]_{2}$ and poly $(\mathrm{dG}-\mathrm{dC})]_{2}$ : interaction with molecular oxygen studied by porphyrin triplet-triplet absorption and singlet oxygen luminescence. J. Photochem. Photobiol. B: Biol. 1998, 42, 181-190. 
20. G. M. Gelfuso, T. Gratieri, J. G. Souza, J. A. Thomazine, R. F. V. Lopez, The influence of positive and negative charges in the passive and iontophoretic skin penetration of porphyrin used in photodynamic therapy. Eur. J. Pharm. Biopharm. 2011, 77, 249-256.

21. $\mathrm{TEG}_{12} \mathrm{PH}_{2}$ and $\mathrm{TEG}_{12} \mathrm{PZn}$ are both oils soluble/miscible with the relevant solvents.

22. A. D. Adler, F. R. Longo, J. D. Finarelli, J. Goldmacher, J. Assour, L. Korsakoff, A simplified synthesis for meso-tetraphenylporphyrin. J. Org. Chem. 1967, 32, 476.

23. J. W. Albery, P. N. Bartlett, C. C. Jones, L. R. Milgrom, Facile Aerial Oxidation of a Porphyrin. Part 2. Mesotetrakis(pyrogallyl)porphyrin. J. Chem. Res., Synop., 1985, 12, 364-365.

24. G. H. Barnett, M. F. Hudson, K. M. Smith, Concerning meso-tetraphenylporphyrin purification. J. Chem. Soc., Perkin Trans. 1, 1975, 14, $1401-1403$.

25. S. H. Lee, H.-J. Kim, Supramolecular functionalization of single-walled carbon nanotubes with uncharged water-soluble porphyrins. J. Porphyrins Phthalocyanines, 2008, 12, 109-115.

26 T. Mori, M. Akamatsu, K. Okamoto, M. Sumita, Y. Tateyama, H. Sakai, J. P. Hill, M. Abe, K. Ariga, Micrometer-level naked-eye detection of caesium particulates in the solid state. Sci. Technol. Adv. Mater., 2013, 14, 015002.

27. J. W. Buchler, In The Porphyrins; Dolphin, D., Ed.; Academic Press: New York, 1978; Vol. I, Part A, p 390.

28. A. L. Wolfe, K. K. Duncan, J. P. Lajiness, K. Zhu, A. S. Duerfeldt, D. L. Boger, A Fundamental Relationship between Hydrophobic Properties and Biological Activity for the Duocarmycin Class 
of DNA-Alkylating Antitumor Drugs: Hydrophobic-Binding-Driven Bonding. J. Med. Chem., 2013, $56,6845-6857$.

29. J. J. M. Lamberts, D. R. Schumacher, D. C. Neckers, Novel rose Bengal derivatives: synthesis and quantum yield studies. J. Am. Chem. Soc. 1984, 106, 5879-5883.

30. J. Godard, F. Brégier, P. Arnoux, B. Myrzakhmetov, Y. Champavier, C. Frochot, V. Sol, New phenalenone derivatives: synthesis and evaluation of their singlet oxygen quantum yields. ACS Omega 2020, 5, 28264-28272.

31. P. G. Mahajan, N. C. Dige, B. D. Vanjare, C.-H. Kim, S.-Y. Seo, K. H. Lee, Design and synthesis of new porphyrin analogues as potent photosensitizers for photodynamic therapy: spectroscopic approach. J. Fluoresc. 2020, 30, 397-406.

32. T. Aida, A. Takemura, M. Fuse, S. Inoue, Synthesis of novel amphiphilic porphyrin carrying water-soluble polyether side chains of controlled chain length. Formation of a cofacial molecular assembly in aqueous media. Chem. Commun. 1988, $391-393$.

33. M. Kořínek, R. Dědic, A. Molnár, A. Svoboda, J. Hála, A comparison of photosensitizing properties of meso-tetraphenylporphyrin in acetone and in dimethylsulfoxide. J. Mol. Struct. $2005,744-747,727-731$.

34. A. A. Abdel-Shafi, D. R. Worrall, A. Y. Ershoy, Photosensitized generation of singlet oxygen from ruthenium(II) and osmium(II) bipyridyl complexes. Dalton Trans. 2004, 30-36.

35. F. Wilkinson, Quantum yields for the photosensitized formation of the lowest electronically excited singlet state of molecular oxygen in solution. J. Phys. Chem. Ref. Data 1993, 22, 113-262. 
36. R. Schmidt, E. Ashfari, Effect of solvent on the phosphorescence rate constant of singlet molecular oxygen $\left({ }^{1} \Delta_{\mathrm{g}}\right)$. J. Phys. Chem. 1990, 94, 4377-4378.

37. R. Lauceri, S. Gurrieri, E. Bellachio, A. Contino, L. Monsu'scolaro, A. Romeo, A. Toscano, R. Purrello, J-type aggregates of the anionic meso-tetrkis(4-sulfonatophenyl)porphine induced by “hindered" cationic porphyrins. Supramol. Chem. 2000, 12, 193 - 202.

38. B. P. Borah, S. Majumder, K. D. Borah, J. Bhuyan, The quest for a better understanding of ethanol coordination to magnesium and zinc porphyrin: a combined experimental and theoretical study. J. Mol. Struct. 2021, 1230, 129646.

39. D. T. Payne, W. A. Webre, H. Gobese, Y. Matsushita, P. A. Karr, M. K. Chahal, J. Labuta, J. S. Fossey, K. Ariga, F. D'Souza, J. P. Hill, Nanomolecular singlet oxygen photosensitizers based on hemiquinonoid-resorcinarenes, the fuchsonarenes. Chem. Sci. 2020, 11, 2614-2620.

40. J. Hynek, D. T. Payne, M. K. Chahal, F. Sciortino, Y. Matsushita, L. K. Shrestha, K. Ariga, J. Labuta, Y. Yamauchi, J. P. Hill, Enhancement of singlet oxygen generation based on incorporation of oxoporphyrinogen (OxP) into microporous solids. Mater. Chem. Today 2021, 21, 100534. 